\title{
Helping Safeguard Veterans Affairs' Hospital Buildings by Advanced Earthquake Monitoring
}

The integrity of the Nation's hospitals is vital for the survival and functioning of the society in the aftermath of a catastrophic earthquake.

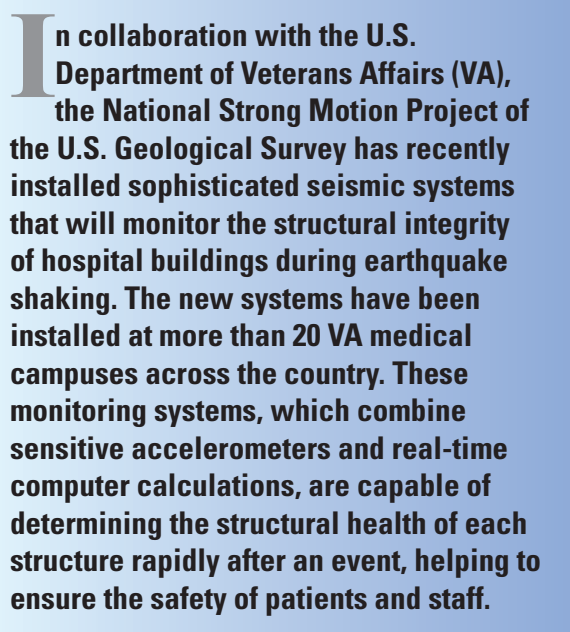

Following the 1971 magnitude 6.6 San Fernando earthquake in Southern California, which resulted in the collapse of several hospital buildings, the U.S. Department of Veterans Affairs (VA) established its Seismic Vulnerability Assessment Program to identify and strengthen VA hospital buildings that needed to be brought up to acceptable seismic safety standards. An important component of this program is monitoring earthquake shaking in hospital buildings. Shortly after the 1971 earthquake, the U.S. Geological Survey (USGS) collaborated with the VA on installing analog accelerographs in 60 VA hospital buildings across the country. These accelerographs were mostly

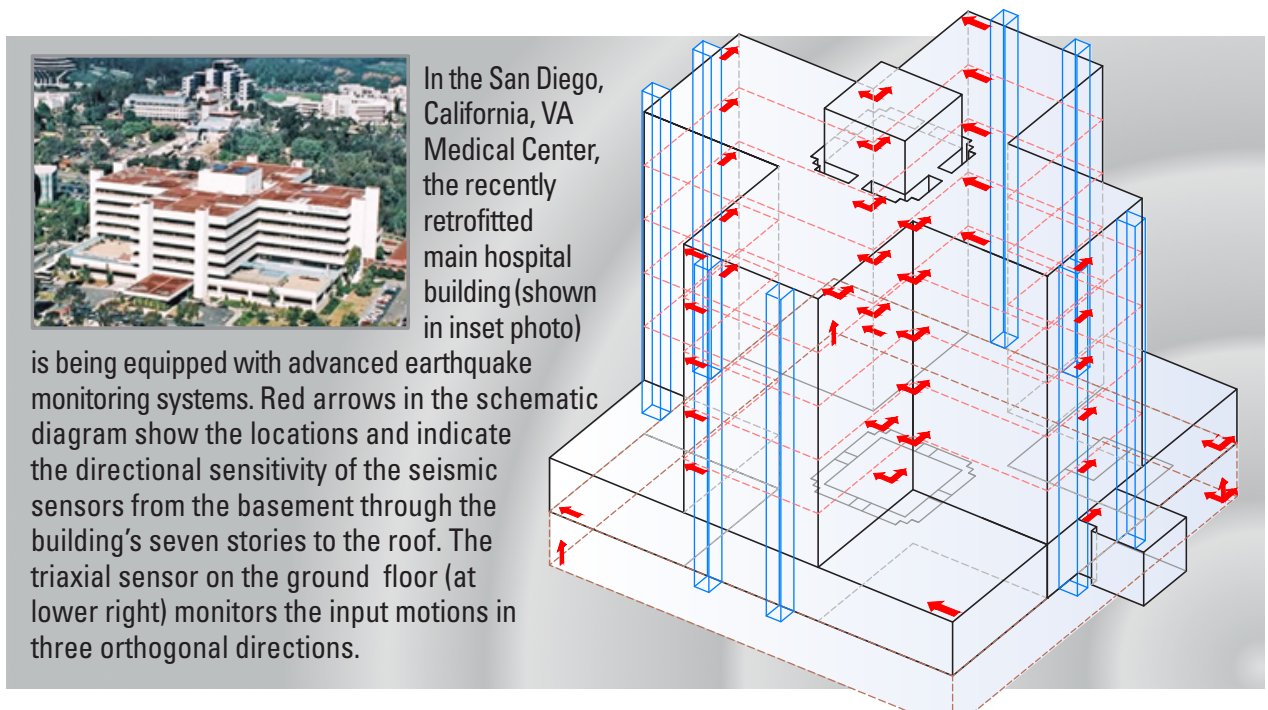

placed on the base level of the buildings. Because these instruments recorded on photographic film, it often took many days or even weeks after an earthquake to process and analyze the records. Later, in 2003, 45 of these seismic monitoring instruments were replaced by modern digital systems. Since 2008 , more than 20 VA medical centers have been instrumented with sophisticated arrays of seismic motion sensors to better understand their response to strong ground shaking during earthquakes. Today, the USGS National Strong Motion Project (NSMP) works closely with the VA to monitor earthquake shaking in more than 70 of their medical centers in earthquake-prone regions

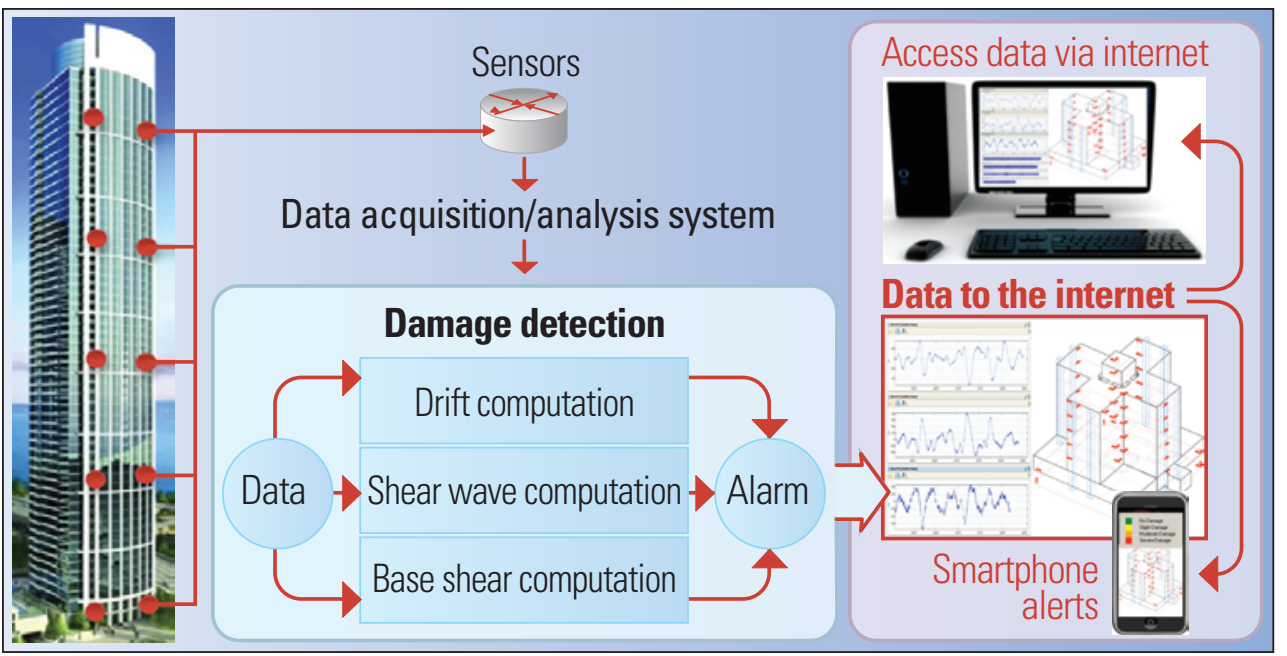

Flow chart showing the functioning of a real-time earthquake monitoring system for instrumented buildings. The system provides important information on the structural health of the building. After a significant earthquake, its near-real-time data analysis capabilities help to rapidly assess building safety. across the counterminous United States, in Alaska, and in Puerto Rico. These monitored structures are part of a larger network of more than 250 structures instrumented under the USGS Advanced National Seismic System (ANSS), which is modernizing and expanding earthquake monitoring around the Nation to improve the overall understanding of earthquakes and their effects on the built environment. Data recorded by these instruments will enable improvement of building design to create more resilient and safer structures that can better protect people and resources.

\section{Monitoring Earthquake Shaking at VA Medical Centers}

An important goal of VA hospitals is to be able to continue to operate and serve the patient community after a major earthquake. However, the building itself may have been damaged and, consequently, may pose a hazard to patients and staff. It is critical that hospital management have the tools and information necessary to make a rapid decision whether to evacuate or not. Early assessment of the integrity of the hospital buildings affected by the quake is valuable in this decisionmaking process. For resilience and sustainability of the Nation's hospitals, it is also necessary to assess their structural condition periodically in order to facilitate necessary repairs and retrofitting measures. 
In response to these needs, the VA Seismic Vulnerability Assessment Program, together with the USGS NSMP, created a new initiative in 2008 to develop an advanced earthquake monitoring system for VA medical centers. This advanced system has two parts - sensing and analysis. The sensing part comprises a dense array of motion sensors, installed permanently at each floor of a building, and rapid data transmission and acquisition. The analysis part consists of several data processing modules integrated into an open-source software package that compresses a large amount of measured data into useful information for assessing the condition of a building before and after an earthquake.

The USGS has already instrumented 21 VA hospital buildings located in quake-prone regions across the country (see map) with sophisticated systems of multiple seismic motion sensors, and similar instrumentation is planned at 7 additional hospital buildings. The number of sensors deployed in each building varies, depending on the floor area, the number of stories, and the number of blocks (or wings) in the building. For instance, the main hospital building at the VA medical center in San Diego, California, will have a seismic array of 60 sensors. Locations for these sensors are strategically selected where the maximum response is expected, mostly at the edges of floors. Every story in each similarly instrumented building has at least three seismic motion sensors oriented horizontally in two orthogonal directions to detect building motion along the reference east-west and north-south directions. Floor rotation around the vertical axis can be computed from the recordings of sensors located at different points. Each building also has a triaxial sensor located on the ground floor, which records the input motions in three orthogonal directions at this level. Additional vertically oriented sensors allow the building's rocking motions to be computed. Specifically, the instrumentation within each building is designed to record:

- the swaying and twisting of the building,

- the time it takes seismic waves to travel from the foundation to the roof, and

- how the frame of the building changed during the earthquake.

Other seismic motion sensors located away from the building record free-field ground shaking, which provides input for USGS Shakemaps. These computer-generated graphics depict ground motion and shaking intensity after significant earthquakes, giving a quick visual representation of a quake's shaking behavior for emergency response.

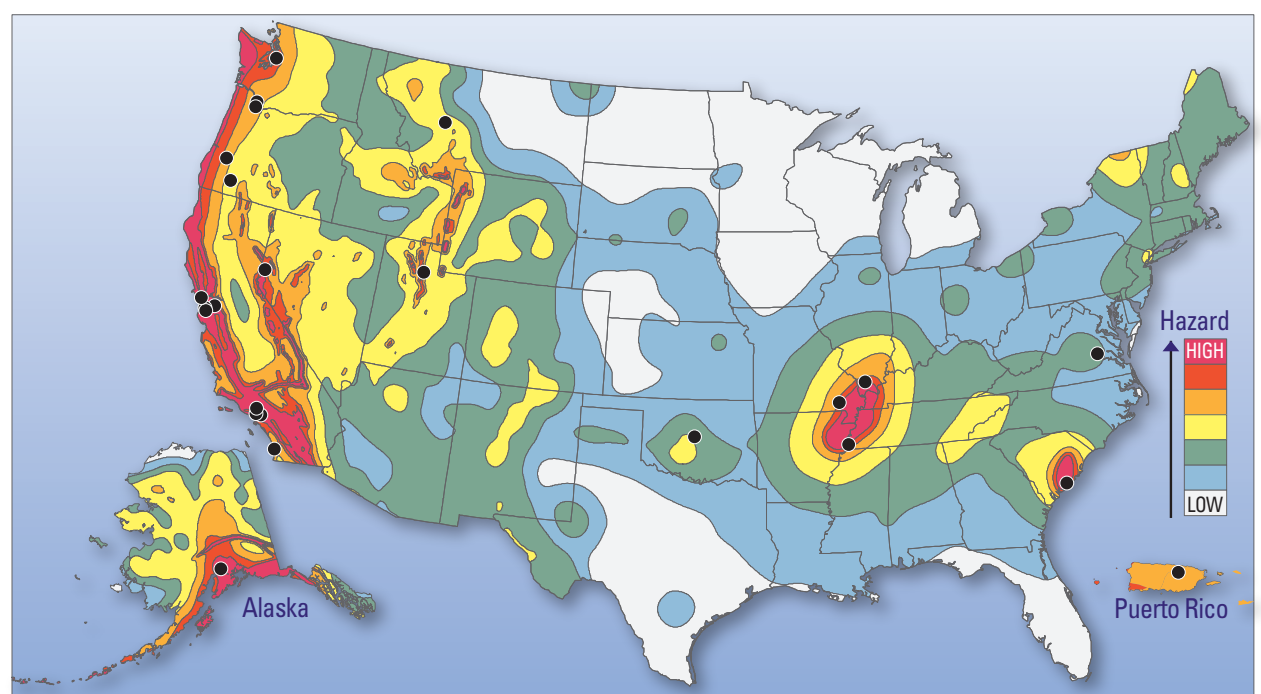

Seismic hazard map of the conterminous United States, Alaska, and Puerto Rico, showing the locations of 28 VA medical centers (black dots) - 21 of these are already equipped with advanced earthquake monitoring systems, and the remainder will be by the end of 2013. Most of these hospital buildings are located in regions of high or very high seismic hazard. By placing shaking sensors in hospital buildings in quake-prone regions of the country, the U.S. Geological Survey and VA are acquiring data critical for reducing future losses arising from structural damage and collapse. (The seismic hazard map is at http://pubs.usgs.gov/fs/2008/3018/.)

\section{Assessing a Building's Structural Health and Detecting Damage}

After a major earthquake it is imperative to monitor the condition of hospital buildings in near-real time in order to be able to assess their structural integrity immediately. Structural health monitoring is achieved by the array of sensors in the building and an open-source on-site data analysis system. This innovative system provides information about how buildings move and distort during shaking and where possible damage likely occurred. Several independent algorithms check for variations in movements of a building frame and its vibration characteristics, for travel time of seismic waves between foundation and roof, and for exceedance of the building's seismic design capacity. If the damage detection algorithms agree, alarm messages are sent (see the flow chart on previous page).

This information allows rapid assessment of building safety in the aftermath of a major quake and supports decisions about necessary repairs, replacements, and other maintenance and rehabilitation measures. In the long run, this system also monitors the building's structural components for indications of deterioration and fatigue, enabling the building to be made more resilient and sustainable through improved maintenance. Recordings from structuralhealth monitoring systems are critical to designing safer hospitals and other buildings and to preventing loss of life. In particular they will help engineers to:

- assess building safety immediately following a damaging quake,
- understand how damage to structural and nonstructural components (such as equipment and pipes) occurs from strong shaking,

- evaluate and improve earthquake-resistant design techniques and also methods for predicting the seismic performance of structures, and

- improve earthquake-resistant design provisions of building codes.

These efforts in turn will help the U.S. Department of Veterans Affairs safeguard its building inventory from future earthquake losses.

Erol Kalkan ${ }^{1}$, Krishna Banga 2, Hasan S. Ulusoy, Jon Peter B. Fletcher', William S. Leith ${ }^{4}$, and James L. Blair ${ }^{l}$

${ }^{1}$ U.S. Geological Survey, Menlo Park, Calif.
${ }^{2}$ U.S. Department of Veterans Affairs, Washington, D.C.
${ }^{3} 22$ Coleman Avenue, Menlo Park, Calif.
${ }^{4}$ U.S. Geological Survey, Reston, Va.

Edited by Peter H. Stauffer

Graphic design by Jeanne S. DiLeo

COOPERATING ORGANIZATIONS

U.S. Department of Veterans Affairs

For more information, contact:

Earthquake Science Center U.S. Geological Survey

Menlo Park, CA 94025

http://earthquake.usgs.gov/

Earthquake Information Hotline: (650) 329-4085

This Fact Sheet and any updates to it are available online at:

http://pubs.usgs.gov/fs/2012/3094/ 